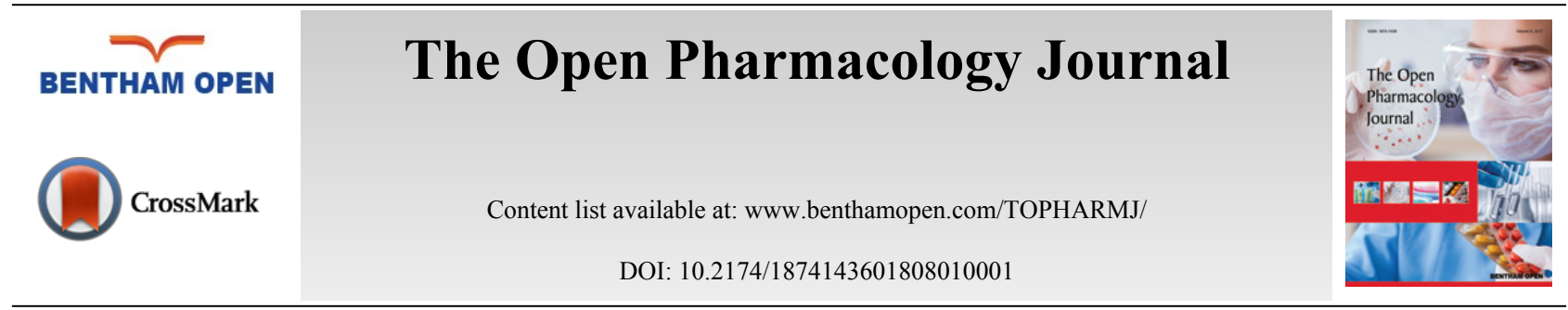

RESEARCH ARTICLE

\title{
Social State Influences Memory in Novel Object Recognition Test Through Oxidative Stress Balance in Male Rats
}

\author{
Hamidreza Famitafreshi ${ }^{1}$ and Morteza Karimian ${ }^{2, *}$ \\ ${ }^{I}$ Department of Physiology, Tehran University of Medical Science, International Campus, Tehran, Iran \\ ${ }^{2}$ Department of Physiology, Tehran University of Medical Science, Tehran, Iran
}

Received: February 10, 2018

Revised: May 03, 2018

Accepted: May 16, 2018

\begin{abstract}
:
Objective:

Social isolation is associated with adverse effects on brain functions. According to previous studies, the reduction of oxidative stress improves cognitive functions. Memory performance is dependent on hippocampus and prefrontal function. The aim of this study is to show that impairment of memory in object recognition test in isolation state is accompanied by deregulation of oxidative stress balance in related areas.
\end{abstract}

\section{Methods and Materials:}

In this study, 14 male Sprague-Dawley rats were randomly divided into two groups as follows: social and isolation. Socialization and isolation plus one week of acclimatization occurred for fourteen days. At the end of the study, after performing behavioral test, (novel object recognition test) rats were anesthetized and sacrificed. After preparation of tissues in controlled condition, oxidative stress status in hippocampus and prefrontal cortex for Malondialdehyde (MDA), glutathione and nitrite/nitrate was assessed.

\section{Results:}

MDA in the hippocampus and prefrontal cortex was higher in isolated rats compared to social rats. Glutathione and nitrite/nitrate in the hippocampus and prefrontal cortex were lower in isolated rats compared to social rats. Memory performance in novel object recognition test both in short term and long term was better in social rats.

\section{Conclusion:}

Memory performance in novel object recognition test is influenced by social and oxidative stress status. So improving memory is possible through socialization and improvement of antioxidant status.

Keywords: Malondialdehyde, Glutathione, Nitrite/nitrate, Novel object recognition test and isolation, Oxidative stress, Prefrontal function.

\section{INTRODUCTION}

Alternation of behavior with changing environment has been well proved in previous studies [1]. Different aspects of behavior will be changed by changing the environment with different mechanisms. Changing environment will affect behavior in all ages and will continue its effects to adulthood. For example, in one experiment, adolescent social isolation changes cognition in adulthood [2]. Also, social isolation can have immediate and long-term effects [3]. The environment in animal studies is mainly divided into social and isolated environment. The social environment has a positive impact on behavior and the isolated environment has a negative impact on behavior.

\footnotetext{
* Address correspondence to this author at the Department of Physiology, Tehran University of Medical Science, Enghelab St, Poorsina St, Tehran, Iran; Tel: 009802166419484; E-mail: karimian@tums.ac.ir
} 
Previous studies have been well defined that social isolation increases the risk of development of depression [4], cognitive decline [5], mortality and morbidity [6]. However, these adverse effects are regardless of the definition of social isolation. Living alone, having a small social network, infrequent participation in social activities, and feelings of loneliness are all considered as social isolation [7].

The aspects of the adverse effect of social isolation that is important to be investigated is to address if the adverse effects have permanent effects on the brain or they will alleviate with socialization. It is believed that if social isolation occurs in the neonate, it will predispose the neonate to develop psychological disorders in adulthood [8]. The negative effects of social isolation especially post-weaning are mostly emotional disorders such as aggression and anxiety-like behaviors $[9,10]$. In adulthood, social isolation may reduce cognitive abilities by decreasing neurogenesis [11]. Also, in adulthood, social isolation predisposes individuals to develop high-risk behavior and in turn may leave permanent sideeffects [12].

Dementia and cognitive disorders that interfere with normal daily function occur in $6.5 \%$ of people with more than 65 years of aging [13]. The Alzheimer's dementia (AD), Vascular Dementia (VD), Dementia with Lewy Bodies (DLB) and frontotemporal dementia (FTD) are the most common types of dementia. Impairment of cognition as the result of a decline in memory is central to all these dementias. By considering the global burden of the diseases, delineation of the underlying mechanism is of great importance for prevention and curing of the diseases. It is believed that oxidative stress reduces cognitive abilities [14].

Oxidative stress status based on previous studies is one of the determinants of the function of the brain in different diseases. So considering that, disturbance in oxidative stress status may deteriorate the outcome of diseases with memory dysfunctions, identifying states that improve the proper balance of oxidative stress is of great importance [15].

The purpose of this study is to show that isolation besides its global negative effects on the brain also deregulates oxidative stress in brain tissues such as the hippocampus and prefrontal cortex that are important to memory and cognitive function. So patients with cognitive decline may get benefits of improved cognitive decline by improving oxidative stress status with pair state.

\section{METHODS AND MATERIALS}

\subsection{Animal Care}

Male Sprague-Dawley rats 8 to 10 weeks (200-250 g) were obtained from animal house of physiology department of Tehran University of Medical Sciences and kept in controlled conditions (12 h light/12 h dark cycle at controlled temperature $\left(22 \pm 2{ }^{\circ} \mathrm{C}\right)$ and humidity $(50 \% \pm 5 \%)$ ) in the Plexiglas cages with providing ad libitum access to food and water. Animals were handled, trained and tested during the light cycle. All experimental protocols were in accordance with the Animal Ethics Committee of Tehran University of Medical Sciences. In this study, male Sprague-Dawley rats weighing about 200-250 grams were used. In each group, 7 rats were used. Overall 7 rats were used for inducing socialization (one by one). It means in each cage, two rats were put together to induce socialization state.

\subsection{Experimental Procedure}

After one week of acclimatization, rats were divided randomly into two groups: isolated and socialized. After 14 days of isolation and socialization, during 3 days, memory was assessed with Novel Object Recognition Test ((NOR) Test). Then, on day 17, rats were sedated and anesthetized with xylazine and ketamine. Then the brains were immediately removed and frozen with liquid nitrogen. For assessing stress-oxidative indices, the prefrontal cortex and hippocampus were homogenized with buffer phosphate. After adding the staining solution, oxidative stress indices were assessed with a spectrophotometer.

\subsection{Isolation}

Isolation of rats were kept in small cages $(27 \times 15 \times 21)$. During isolation, rats had free access to food and water. The light-dark cycle was not disturbed.

\subsection{Socialization}

For inducing socialization state, rats was done in large cages $(45 \times 15 \times 21)$. During socialization, rats had free accessed to food and water. The light-dark cycle was not disturbed. 


\subsection{Preparation of Tissues for Assessing Oxidative Stress Markers}

The brain immediately removed from the skull and was immediately was frozen with liquid nitrogen and then, was kept in $-70^{\circ} \mathrm{C}$ in a refrigerator. For the preparation of the final homogenized sample, blocks from hippocampus and prefrontal cortex were prepared. They were homogenized with buffer phosphate (1:10).

\subsection{Malondialdehyde Assessment (MDA)}

Total MDA was measured according to Thiobarbituric Acid (TBA) reaction. Simply for performing this analysis, TBA 1\% (Sigma-Aldrich Co.) and Trichloroacetic Acid (TCA) 20\% (Sigma-Aldrich Co.) were mixed together. Then 100 microliter of homogenized sample was added to the above mixture. After 90 minutes of boiling, maximum absorbance was measured at $532 \mathrm{~nm}$ with the spectrometer [16].

\subsection{Glutathione Assessment}

5, 5'-dithiobis-(2-nitrobenzoic acid) (DTNB) was used as the reaction substrate for estimating the amount of reduced glutathione. For performing this experiment, Tris buffer (Sigma-Aldrich Co.), DTNB (Sigma-Aldrich Co.) and methanol (Sigma-Aldrich Co.) were used. 100 microliter of homogenized sample was added to the above mixture. Maximum absorbance was measured at $412 \mathrm{~nm}$ with the spectrometer [17].

\subsection{Nitrite/Nitrate Assessment}

Total Nitrite/Nitrate was assessed according to Griess reaction. Simply for performing this experiment, n-1 (naphthyl) ethylenediamine (NEDD) (Sigma-Aldrich Co.), sulfanilamide (Sigma-Aldrich Co.) and phosphoric acid (Sigma-Aldrich Co.); all were mixed together. 100 microliter of homogenized sample was added to the above mixture. The final solution developed pink color, and maximum absorbance was measured at $540 \mathrm{~nm}$ with the spectrometer [18].

\subsection{Novel Object Recognition Test}

\section{Apparatus, Objects and Data Collection}

The apparatus and procedure were the same as described previously. The experiment was completed in an open field-like arena $(50 \times 50 \times 40 \mathrm{~cm} 3)$, lit up with halogen lamp $(60 \mathrm{~W})$. The experiment is based on spontaneous tendency of rodent to explore the novel object more than the recently explored object. Habituation session was done first in which they could freely explore the empty open field arena for $5 \mathrm{~min}$. On following day, each rat was supposed to familiarization phase during $5 \mathrm{~min}$ to explore two identical objects $(\mathrm{A}+\mathrm{A})$. For assessing short-term memory (STM), 2 $\mathrm{h}$ later, the rat was given 5 min to explore two different objects $(\mathrm{A}+\mathrm{B}) .24 \mathrm{~h}$ after later after familiarization phase, Longterm Memory (LTM) was assessed with a novel object plus the previous object $(\mathrm{A}+\mathrm{C})$. The arena and objects were cleaned with ethanol $70 \%$, after each training session to remove the olfactory cues. The recognition index (RI) measured to determine the ratio of novel object exploration time. It is the main index of retention. Exploration time of an object is specified as pointing the nose at a distance of less than $1 \mathrm{~cm}$ to the object, and/or touching it with the nose. In contrast, turning around, sitting and climbing on the object were not considered as an exploratory behavior [19].

\section{STATISTICS}

Data analysis was performed with SPSS version 22. Two-Tailed independent samples t-test was used to assess the mean difference. Data were represented as mean $\pm \mathrm{SEM}$.

\section{RESULT}

Malondialdehyde (MDA) in hippocampus and prefrontal cortex: MDA in the hippocampus and prefrontal cortex was higher in isolated rats compared to social rats. MDA is an indicator of peroxide production in brain cells. It is negatively correlated with brain function (Figs. 1a and b). 

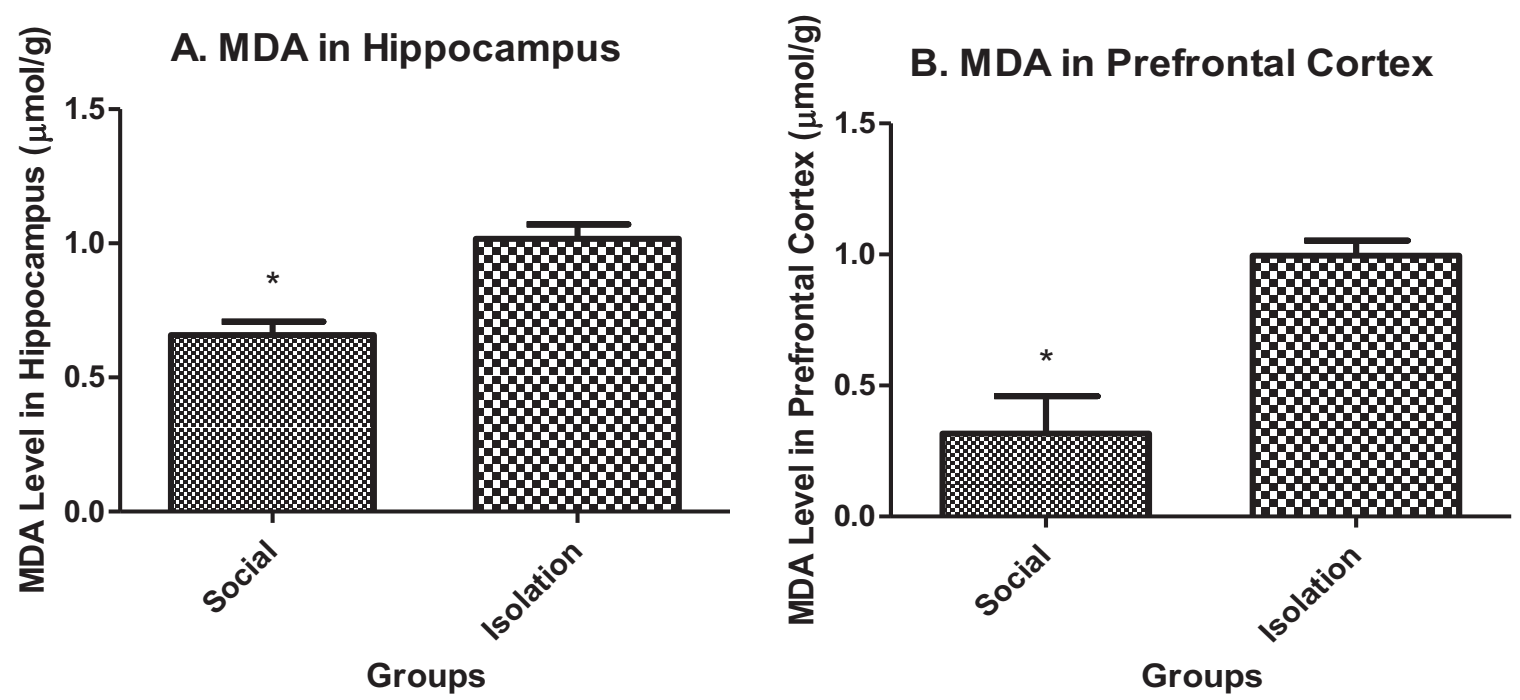

Fig. (1). A.MDA concentration in hippocampus tissue $(n=7)$. B. MDA concentration in prefrontal cortex tissue ( $n=7)$. Data are represented as mean \pm SEM. $*$ was used to show a significant difference for $\mathrm{p}<0.05$.

Glutathione level in hippocampus: Glutathione in the hippocampus and prefrontal cortex were lower in isolated rats compared to social rats. Reduced glutathione is an indicator of antioxidant defense in brain cells. It is positively correlated with brain function (Figs. 2a and b).
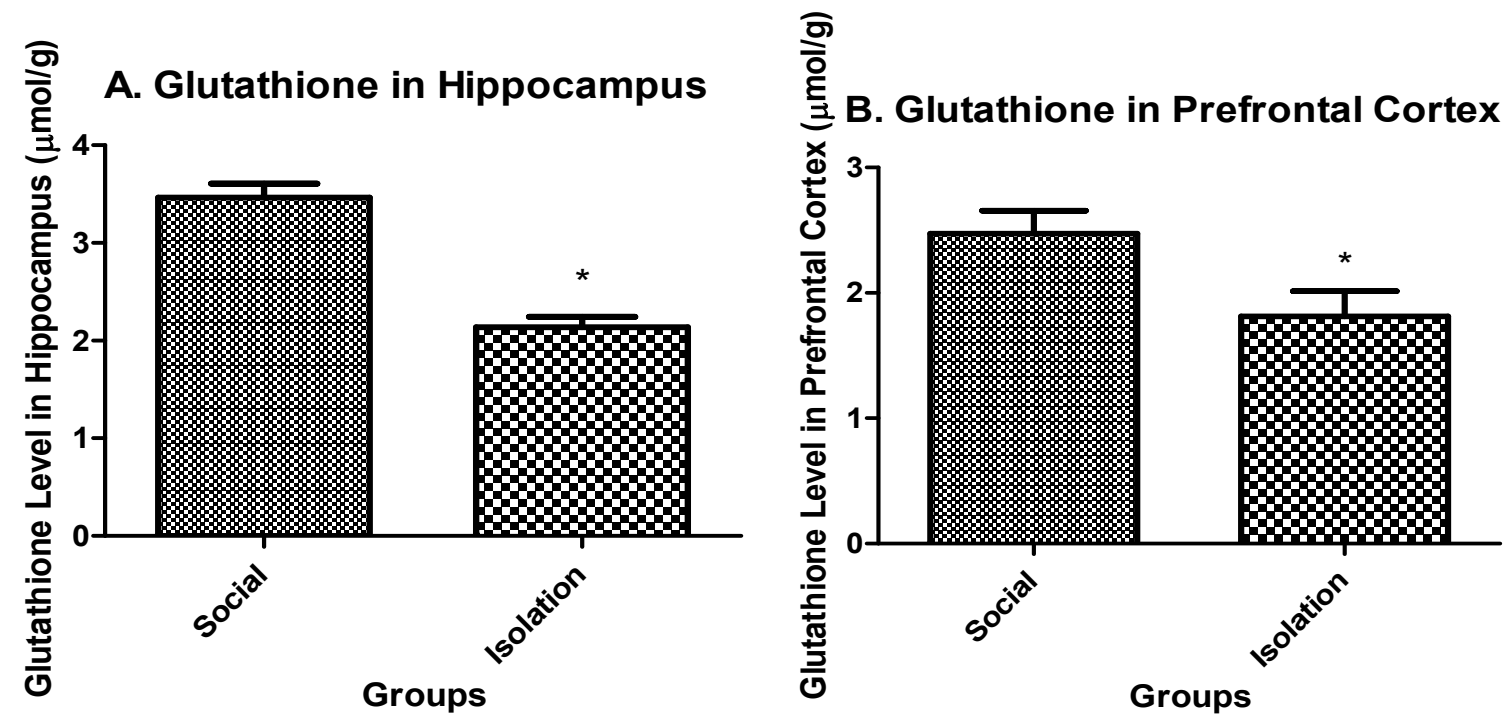

Fig. (2). A.Glutathione concentration in hippocampus tissue $(n=7)$. B. Glutathione concentration in prefrontal cortex tissue ( $n=7)$. Data are represented as mean \pm SEM. * was used to show a significant difference for $\mathrm{p}<0.05$.

Nitrite/nitrate in hippocampus: Nitrite/nitrate in the hippocampus and prefrontal cortex were lower in isolated rats compared to social rats. Nitrite/nitrate is an indicator of antioxidant defense in brain cells. It is positively correlated with brain function (Figs. 3a and $\mathbf{b}$ ). 

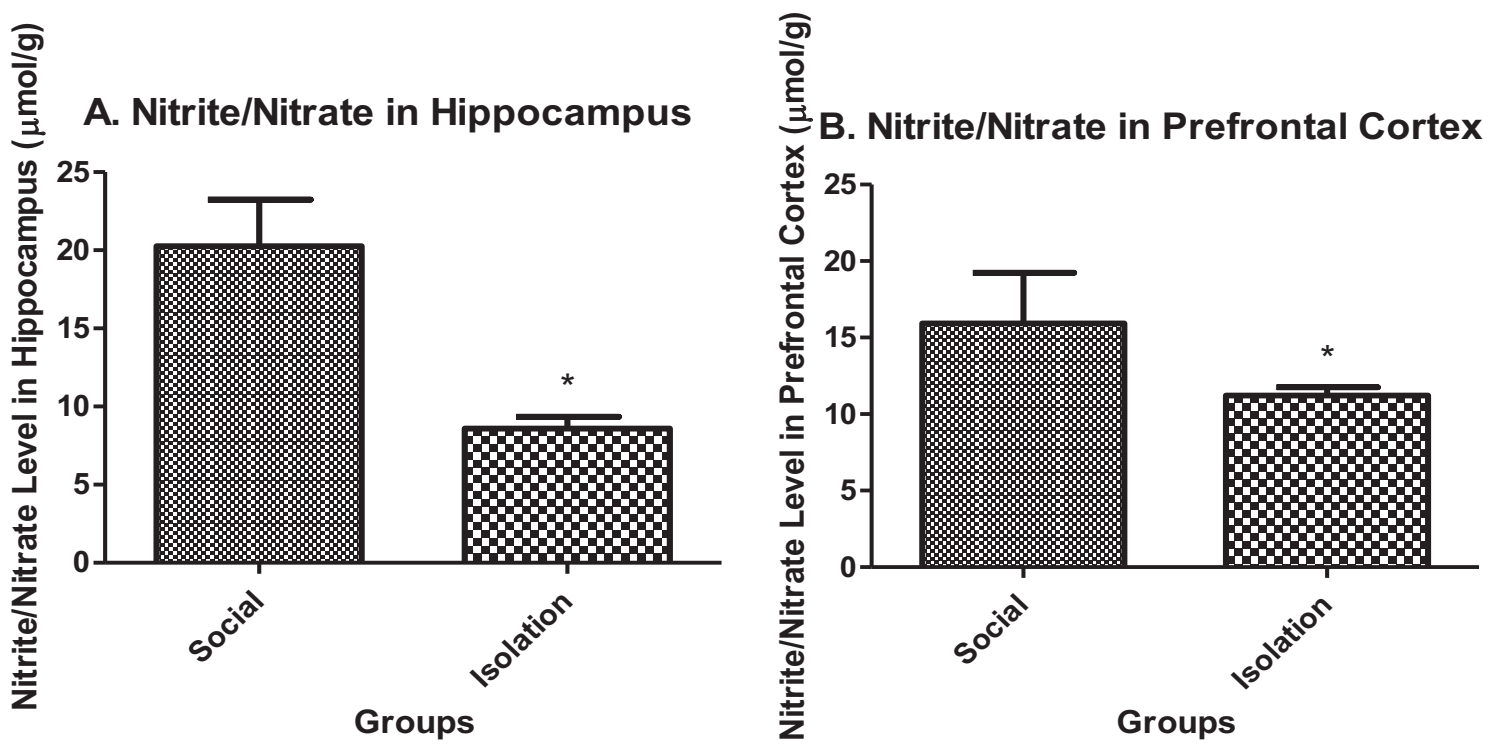

Fig. (3). A.Nitrite/nitrate concentration in hippocampus tissue $(n=7)$. B. Nitrite/nitrate concentration in prefrontal cortex tissue ( $n=7)$. Data are represented as mean \pm SEM. * was used to show a significant difference for $\mathrm{p}<0.05$.

Short-term and long-term memory in novel object recognition test: Short-term memory performance in novel object recognition test was better in social rats compared to isolated rats (Fig. 4a). Also, long-term memory performance in novel object recognition test was better in social rats compared to isolated rats (Fig. $\mathbf{4 b}$ ).
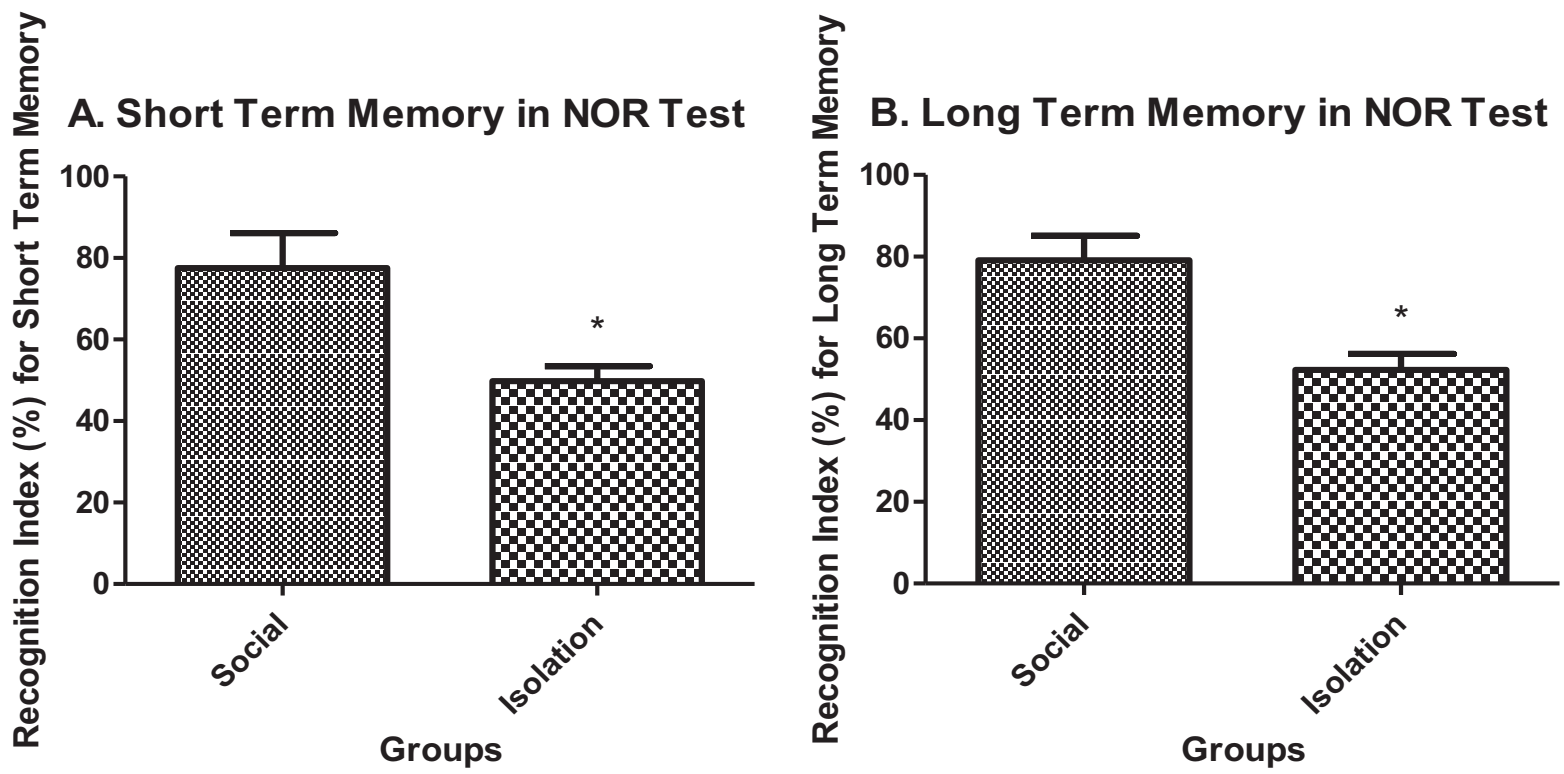

Fig. (4). A.Short term memory performance in novel object recognition test $(n=7)$. B. Long-term memory performance in novel object recognition test $(n=7)$. Data are represented as mean \pm SEM. $*$ was used to show a significant difference for $p<0.05$.

\section{DISCUSSION}

In this study, it has been shown that 1) hippocampus and prefrontal function are necessary for memory and prevention of dementia and 2) improvement of oxidative stress with pair state improves memory.

Novel object recognition test is an experiment that is mainly used for assessing amnesia. This experiment assesses the ability to recognize the previously presented object [20]. However, in different paradigms, it can be used for assessing working memory, attention, novelty, and preference for novelty [21]. Conditioning of remembering of objects 
with environmental cues is another feature of this experiment [22].

Memory formation is a multistage process that is formed in several stages. In this sense, brain structure has a close association with each other. The brain regions of interest in this regard are prefrontal cortex, hippocampus and adjacent areas [23]. Memory formation involves encoding, consolidation, and retrieval. In this process, every part of the related region in the brain has its own role. Memories may occur in the context of other issues, that in this regard, the formation of memory has a distinct mechanism. It is important because the close association of brain-related structures such as the hippocampus and prefrontal cortex is necessary [23].

In object recognition test, rats are employed with surrounding cues to show their natural habit of exploring novel object for recognizing the new object. In this sense, hippocampus and prefrontal cortex interplay an important contribution.

Forgetfulness is another factor that should be taken into account when studying dementia and memory. In novel object recognition test, forgetfulness is also tested [24]. In this case, when rats are allowed to explore the object and 24 hours later, rats are again exposed to new objects, natural forgetfulness is also examined. Accelerated forgetfulness is another pathologic condition which occurs in dementias like Alzheimer's disease.

In this study also in accordance with previous studies, brain function was observed to be better in the social state than isolation. Social isolation with different mechanism causes impairment of different functions of the brain. The proposed mechanisms are the reduction in neurogenesis and increase in testosterone [25], Hypothalamus-pituitary Axis (HPA) axis dysfunction [26], MDMA receptor activation [27], overexpression of dopamine receptor [28] and reduction of BDNF [29]. In this study, the novel mechanism was proposed and it was shown that increase in oxidative stress (MDA) and reduction in antioxidant defense (glutathione and nitrite/nitrate) also cause memory decline. Another new finding of this study was this fact that impairment of memory in novel object recognition test was influenced by hippocampus and prefrontal cortex. In previous studies, prefrontal cortex had a less effective role in memory formation [23]. In this study, it was shown that prefrontal cortex in association with hippocampus influences memory formation in NOR test. In this sense, the balance of oxidative stress in hippocampus and prefrontal cortex is necessary to show this interconnected function.

In recent studies, there has been much attention paid to the association of disturbed oxidative stress status and cognitive function. It has been known that many neurologic diseases such as Alzheimer's, Parkinson's, Huntington's, Major depressive disorder and cognitive decline due to aging are associated with disturbed oxidative-stress [30]. Several mechanisms have been proposed. In Alzheimer's disease, BDNF, GSK3ß, CREB, and Aß alternation have been implicated in the pathogenesis of the disease [31]. Also in these disorders, dysfunction of prefrontal cortex besides hippocampus has also been reported [32]. Also, reduction of neurogenesis is another explanation for the reduction of cognitive abilities in Alzheimer's disease [33]. Increased inflammation in brain tissue in Alzheimer's disease has also been observed. The anti-inflammatory cytokines such as IL-10 have alleviated the cognitive deficits in Alzheimer's disease patients [34].

In Parkinson's disease, other mechanisms have been postulated. Lewy bodies (intracytoplasmic aggregations inside dopaminergic neurons of substantia nigra) cause oxidative stress and the consequent reduction in the survival of neurons [35]. Besides this imbalance, other disturbances such as alternation in BDNF level in the striatum [36], serotonergic and catecholaminergic neurons develop [37].

In Huntington's disease, another case appears . Huntingtin mutated gene causes the formation of an unnatural protein that is called mutant Huntingtin protein. This abnormal protein interferes with normal trafficking of intracellular transportation. The mutated product causes dysfunction in normal mitochondrial function and reduces ATP production and increases the rate of production of reactive oxygen [38].

In aged people (more than 80 years old), cognitive declines develop. The most organs that are affected are hippocampus [39]. Also, the prefrontal cortex is one of the most prevalent organs that are affected [40]. For cognitive decline in aging, several mechanisms have also been proposed such as deregulation of monoamine neurons and BDNF [41] and increase in proinflammatory cytokines such as TNF- $\alpha$ and interleukin-1ß (IL-1ß) [42].

On the other hand, along with dementia psychiatric disorders may develop. Oxidative stress balance is assumed to be important for the prevention of the development of such disorders [43]. The frontal lobe is the most sensitive organ that is suspected to be involved in this regard. 


\section{CONCLUSION}

In this study, it was shown that social isolation has a negative impact on memory formation in object recognition test. In this sense, hippocampus and prefrontal cortex are working together since the similar impairment in oxidative stress happens in both the organs. In this study, also one more time, the interconnected function of hippocampus and prefrontal cortex in memory formation and forgetfulness was shown. Social state besides increasing the oxidative stress of hippocampus and prefrontal cortex (as assessed by MDA) also reduces antioxidant defense (as assessed by glutathione and nitrite/nitrate). In this manner, social isolation has a devastating effect on memory formation and forgetfulness . Behaviour is, therefore, assessed on the basis of both previous information and internal estimates of conditional probabilities in novel object recognition test, so just proper storage of previous information is not sufficient in this test.

\section{ETHICS APPROVAL AND CONSENT TO PARTICIPATE}

The study was approved by the Animal Ethics Committee of Tehran University of Medical Sciences and was conducted in compliance with the guidelines.

\section{HUMAN AND ANIMAL RIGHTS}

No humans were used in the experiments. All the reported experiments involving animals used in the study were in accordance with the Animal Ethics Committee of Tehran University of Medical Sciences.

\section{CONSENT FOR PUBLICATION}

Not applicable.

\section{CONFLICT OF INTEREST}

The authors declare no conflict of interest, financial or otherwise.

\section{ACKNOWLEDGEMENTS}

Declared none.

\section{REFERENCES}

[1] Niwa M, Jaaro-Peled H, Tankou S, et al. Adolescent stress-induced epigenetic control of dopaminergic neurons via glucocorticoids. Science 2013; 339(6117): 335-9.

[http://dx.doi.org/10.1126/science.1226931] [PMID: 23329051]

[2] Shao F, Han X, Shao S, Wang W. Adolescent social isolation influences cognitive function in adult rats. Neural Regen Res 2013; 8(11): 1025-30.

[PMID: 25206396]

[3] Cruz FC, Duarte JO, Leão RM, Hummel LF, Planeta CS, Crestani CC. Adolescent vulnerability to cardiovascular consequences of chronic social stress: Immediate and long-term effects of social isolation during adolescence. Dev Neurobiol 2016; 76(1): 34-46. [http://dx.doi.org/10.1002/dneu.22297] [PMID: 25914339]

[4] Zanier-Gomes PH, de Abreu Silva TE, Zanetti GC, et al. Depressive behavior induced by social isolation of predisposed female rats. Physiol Behav 2015; 151: 292-7.

[http://dx.doi.org/10.1016/j.physbeh.2015.07.026] [PMID: 26209499]

[5] Whitehouse C. The effects of social isolation on cognition: Social loneliness reduces cognitive performance in older adults. A thesis presented in partial fulfilment of the requirement for the degree of Master of Science in Psychology at Massey University, Palmerston North, New Zealand, 2013.

[6] Eisele M, Zimmermann T, Köhler M, et al. Influence of social support on cognitive change and mortality in old age: results from the prospective multicentre cohort study AgeCoDe. BMC Geriatr 2012; 12 : 9. [http://dx.doi.org/10.1186/1471-2318-12-9] [PMID: 22433223]

[7] Cornwell EY, Waite LJ. Social disconnectedness, perceived isolation, and health among older adults. J Health Soc Behav 2009; 50(1): 31-48. [http://dx.doi.org/10.1177/002214650905000103] [PMID: 19413133]

[8] Lukkes JL, Engelman GH, Zelin NS, Hale MW, Lowry CA. Post-weaning social isolation of female rats, anxiety-related behavior, and serotonergic systems. Brain Res 2012; 1443: 1-17. [http://dx.doi.org/10.1016/j.brainres.2012.01.005] [PMID: 22297173]

[9] Lukkes JL, Watt MJ, Lowry CA, Forster GL. Consequences of post-weaning social isolation on anxiety behavior and related neural circuits in rodents. Front Behav Neurosci 2009; 3: 18. 
[http://dx.doi.org/10.3389/neuro.08.018.2009] [PMID: 19738931]

[10] Toth M, Mikics E, Tulogdi A, Aliczki M, Haller J. Post-weaning social isolation induces abnormal forms of aggression in conjunction with increased glucocorticoid and autonomic stress responses. Horm Behav 2011; 60(1): 28-36. [http://dx.doi.org/10.1016/j.yhbeh.2011.02.003] [PMID: 21316368]

[11] McCormick CM, Thomas CM, Sheridan CS, Nixon F, Flynn JA, Mathews IZ. Social instability stress in adolescent male rats alters hippocampal neurogenesis and produces deficits in spatial location memory in adulthood. Hippocampus 2012; 22(6): 1300-12. [http://dx.doi.org/10.1002/hipo.20966] [PMID: 21805526]

[12] Zamberletti E, Viganò D, Guidali C, Rubino T, Parolaro D. Long-lasting recovery of psychotic-like symptoms in isolation-reared rats after chronic but not acute treatment with the cannabinoid antagonist AM251. Int J Neuropsychopharmacol 2012; 15(2): 267-80. [http://dx.doi.org/10.1017/S1461145710001185] [PMID: 20923599]

[13] Matthews FE, Arthur A, Barnes LE, et al. A two-decade comparison of prevalence of dementia in individuals aged 65 years and older from three geographical areas of England: results of the Cognitive Function and Ageing Study I and II. Lancet 2013; 382(9902): 1405-12. [http://dx.doi.org/10.1016/S0140-6736(13)61570-6] [PMID: 23871492]

[14] Newton DF, Naiberg MR, Goldstein BI. Oxidative stress and cognition amongst adults without dementia or stroke: Implications for mechanistic and therapeutic research in psychiatric disorders. Psychiatry Res 2015; 227(2-3): 127-34. [http://dx.doi.org/10.1016/j.psychres.2015.03.038] [PMID: 25892258]

[15] Famitafreshi H, Karimian M. Sociality influences oxidative stress indices in ventral tegmental area and tendency for drugs in male rats. Electronic J Biol 2017; 13: 2.

[16] Zhang H, Wang ZY, Yang L, Yang X, Wang X, Zhang Z. In vitro antioxidant activities of sulfated derivatives of polysaccharides extracted from Auricularia auricular. Int J Mol Sci 2011; 12(5): 3288-302. [http://dx.doi.org/10.3390/ijms12053288] [PMID: 21686185]

[17] Khan RA, Khan MR, Sahreen S. Brain antioxidant markers, cognitive performance and acetylcholinesterase activity of rats: Efficiency of Sonchus asper. Behav Brain Funct 2012; 8: 21. [http://dx.doi.org/10.1186/1744-9081-8-21] [PMID: 22591917]

[18] Miranda KM, Espey MG, Wink DA. A rapid, simple spectrophotometric method for simultaneous detection of nitrate and nitrite. Nitric Oxide 2001; 5(1): 62-71.

[http://dx.doi.org/10.1006/niox.2000.0319] [PMID: 11178938]

[19] N'Go PK, Azzaoui FZ, Soro PR. Developmental effects of malathion exposure on recognition memory and spatial learning in males wistar rats. J Behav Brain Sci 2013; 3(03): 331. [http://dx.doi.org/10.4236/jbbs.2013.33033]

[20] Baxter MG. "I’ve seen it all before": explaining age-related impairments in object recognition. Theoretical comment on Burke et al. (2010). Behav Neurosci 2010; 124(5): 706-9. [http://dx.doi.org/10.1037/a0021029] [PMID: 20939671]

[21] Goulart BK, de Lima MN, de Farias CB, et al. Ketamine impairs recognition memory consolidation and prevents learning-induced increase in hippocampal brain-derived neurotrophic factor levels. Neuroscience 2010; 167(4): 969-73. [http://dx.doi.org/10.1016/j.neuroscience.2010.03.032] [PMID: 20338225]

[22] Ennaceur A. One-trial object recognition in rats and mice: methodological and theoretical issues. Behav Brain Res 2010; $215(2): 244-54$. [http://dx.doi.org/10.1016/j.bbr.2009.12.036] [PMID: 20060020]

[23] Preston AR, Eichenbaum H. Interplay of hippocampus and prefrontal cortex in memory. Curr Biol 2013; 23(17): R764-73. [http://dx.doi.org/10.1016/j.cub.2013.05.041] [PMID: 24028960]

[24] Reger ML, Hovda DA, Giza CC. Ontogeny of Rat Recognition Memory measured by the novel object recognition task. Dev Psychobiol 2009; 51(8): 672-8. [http://dx.doi.org/10.1002/dev.20402] [PMID: 19739136]

[25] Spritzer MD, Ibler E, Inglis W, Curtis MG. Testosterone and social isolation influence adult neurogenesis in the dentate gyrus of male rats. Neuroscience 2011; 195: 180-90. [http://dx.doi.org/10.1016/j.neuroscience.2011.08.034] [PMID: 21875652]

[26] Butler TR, Ariwodola OJ, Weiner JL. The impact of social isolation on HPA axis function, anxiety-like behaviors, and ethanol drinking. Front Integr Nuerosci 2014; 7: 102.

[http://dx.doi.org/10.3389/fnint.2013.00102] [PMID: 24427122]

[27] García-Pardo MP, Blanco-Gandía MC, Valiente-Lluch M, Rodríguez-Arias M, Miñarro J, Aguilar MA. Long-term effects of repeated social stress on the conditioned place preference induced by MDMA in mice. Prog Neuropsychopharmacol Biol Psychiatry 2015; 63: 98-109. [http://dx.doi.org/10.1016/j.pnpbp.2015.06.006] [PMID: 26093344]

[28] Han X, Li N, Xue X, Shao F, Wang W. Early social isolation disrupts latent inhibition and increases dopamine D2 receptor expression in the medial prefrontal cortex and nucleus accumbens of adult rats. Brain Res 2012; 1447: 38-43. [http://dx.doi.org/10.1016/j.brainres.2012.01.058] [PMID: 22341870]

[29] Han X, Wang W, Xue X, Shao F, Li N. Brief social isolation in early adolescence affects reversal learning and forebrain BDNF expression in adult rats. Brain Res Bull 2011; 86(3-4): 173-8. 
[http://dx.doi.org/10.1016/j.brainresbull.2011.07.008] [PMID: 21801814]

[30] Réus GZ, Titus SE, Abelaira HM, et al. Neurochemical correlation between major depressive disorder and neurodegenerative diseases. Life Sci 2016; 158: 121-9.

[http://dx.doi.org/10.1016/j.1fs.2016.06.027] [PMID: 27370938]

[31] Pláteník J, Fišar Z, Buchal R, et al. GSK3ß, CREB, and BDNF in peripheral blood of patients with Alzheimer's disease and depression. Prog Neuropsychopharmacol Biol Psychiatry 2014; 50: 83-93. [http://dx.doi.org/10.1016/j.pnpbp.2013.12.001] [PMID: 24334212]

[32] Van der Mussele S, Bekelaar K, Le Bastard N, et al. Prevalence and associated behavioral symptoms of depression in mild cognitive impairment and dementia due to Alzheimer's disease. Int J Geriatr Psychiatry 2013; 28(9): 947-58. [http://dx.doi.org/10.1002/gps.3909] [PMID: 23255479]

[33] Iascone DM, Padidam S, Pyfer MS, Zhang X, Zhao L, Chin J. Impairments in neurogenesis are not tightly linked to depressive behavior in a transgenic mouse model of Alzheimer's disease. PLoS One 2013; 8(11): e79651.

[http://dx.doi.org/10.1371/journal.pone.0079651] [PMID: 24244537]

[34] Holmgren S, Hjorth E, Schultzberg M, et al. Neuropsychiatric symptoms in dementia-a role for neuroinflammation? Brain Res Bull 2014; 108: 88-93.

[http://dx.doi.org/10.1016/j.brainresbull.2014.09.003] [PMID: 25224917]

[35] Schapira AH. Mitochondria in the aetiology and pathogenesis of Parkinson's disease. Lancet Neurol 2008; 7(1): 97-109. [http://dx.doi.org/10.1016/S1474-4422(07)70327-7] [PMID: 18093566]

[36] aan het Rot M, Collins KA, Fitterling HL. Physical exercise and depression. Mt Sinai J Med 2009; 76(2): $204-14$. [http://dx.doi.org/10.1002/msj.20094] [PMID: 19306383]

[37] Aarsland D, Brønnick K, Fladby T. Mild cognitive impairment in Parkinson's disease. Curr Neurol Neurosci Rep 2011; 11(4): 371-8. [http://dx.doi.org/10.1007/s11910-011-0203-1] [PMID: 21487730]

[38] Zielonka D, Mielcarek M, Landwehrmeyer GB. Update on Huntington's disease: Advances in care and emerging therapeutic options. Parkinsonism Relat Disord 2015; 21(3): 169-78.

[http://dx.doi.org/10.1016/j.parkreldis.2014.12.013] [PMID: 25572500]

[39] Wilson IA, Gallagher M, Eichenbaum H, Tanila H. Neurocognitive aging: prior memories hinder new hippocampal encoding. Trends Neurosci 2006; 29(12): 662-70. [http://dx.doi.org/10.1016/j.tins.2006.10.002] [PMID: 17046075]

[40] Jellinger KA, Attems J. Neuropathological approaches to cerebral aging and neuroplasticity. Dialogues Clin Neurosci 2013; 15(1): 29-43. [PMID: 23576887]

[41] Rao JS, Kellom M, Kim HW, Rapoport SI, Reese EA. Neuroinflammation and synaptic loss. Neurochem Res 2012; 37(5): 903-10. [http://dx.doi.org/10.1007/s11064-012-0708-2] [PMID: 22311128]

[42] Sama DM, Norris CM. Calcium dysregulation and neuroinflammation: Discrete and integrated mechanisms for age-related synaptic dysfunction. Ageing Res Rev 2013; 12(4): 982-95. [http://dx.doi.org/10.1016/j.arr.2013.05.008] [PMID: 23751484]

[43] Newton DF, Naiberg MR, Goldstein BI. Oxidative stress and cognition amongst adults without dementia or stroke: Implications for mechanistic and therapeutic research in psychiatric disorders. Psychiatry Res 2015; 227(2-3): 127-34.

[http://dx.doi.org/10.1016/j.psychres.2015.03.038] [PMID: 25892258]

(C) 2018 Famitafreshi and Karimian.

This is an open access article distributed under the terms of the Creative Commons Attribution 4.0 International Public License (CC-BY 4.0), a copy of which is available at: (https://creativecommons.org/licenses/by/4.0/legalcode). This license permits unrestricted use, distribution, and reproduction in any medium, provided the original author and source are credited. 